\title{
Tingkat Cemaran Logam Berat Pada Air Sungai Batanghari Provinsi Jambi berdasarkan Indeks C/P (Contamination/Pollution)
}

\author{
Shally Yanova ${ }^{1 *}$, Kory Asi Mariana Siagian ${ }^{2}$, dan Rizki Gusanti ${ }^{3}$ \\ ${ }^{1}$ Program Studi Teknik Lingkungan Universitas Jambi \\ Jalan Tribrata KM 11 Pondok Meja, Mestong, Jambi \\ *correspondence e-mail: shallyyanova@gmail.com
}

\begin{abstract}
This research has been conducted in July to August 2020. The purpose of this study is to find out the heavy metal content of $\mathrm{Hg}$, Cd, Pb, Mn, and $F e$ in the Batanghari River water of Jambi Province and determine the level of contamination by referring to PP No.82 Year 2001 . The research site was conducted in Aur Duri 1 and Aur Duri 2 Jambi Provinces. Research on heavy metal content in water was conducted at 6 measurement points consisting of 3 measurement points in the Aur Duri region 1 upper and lower of the river and 3 measurement points in the Aur Duri region 2 the upper and lower of the river. Determination of river water sampling point is done using purposive sampling method. Based on the results of this study, it can be concluded that the Batanghari River water of Jambi Province has been very heavily polluted with $\mathrm{Hg}$ and Fe metals, if referring to PP No.82 Year 2001 Class I. The content of Mn metal in Batanghari River water mostly belongs to the category of fairly polluted metal Mn. While the metal content of $C d$ and Pb belongs to the category is not contaminated.
\end{abstract}

Keywords: Heavy metal; Index C/P; Contamination; Pollution, Batanghari River

\section{Pendahuluan}

Sungai Batanghari Provinsi Jambi merupakan sumber baku utama air PDAM Kota Jambi. Berbagai macam aktivitas di sepanjang Sungai Batanghari seperti pertanian, industri, kompleks Pasar Angso Duo (Pasar Induk Kota Jambi), pertambangan dan objek wisata menjadikan kualitas air Sungai Batanghari harus diperhatikan secara khusus agar tidak tercemar. Berbagai limbah yang dihasilkan dari aktivitas aktivitas tersebut dapat memengaruhi kualitas air Sungai Batanghari, terutama kandungan logam beratnya (Wiriani dkk., 2018 dan Asdak, 2010).

Kualitas air sungai dipengaruhi oleh kualitas pasokan air dari daerah tangkapannya. Kualitas pasokan air dari daerah tangkapan tersebut dipengaruhi oleh berbagai aktivitas manusia yang tercakup di dalamnya (Wiwoho, 2005). Semakin meningkatnya beban pencemar yang masuk ke dalam badan air dapat menyebabkan meningkatnya degradasi lingkungan perairan sehingga memengaruhi daya dukung dan daya tampung perairan (Baherem dkk, 2014 dan Rahman, 2011).

Salah satu bentuk degradasi lingkungan perairan yaitu tingginya kandungan logam berat. Berdasarkan pada hasil penelitian Sahara dan Puryanti (2015), ditemukan bahwa kandungan logam berat $\mathrm{Hg}$ dan $\mathrm{Pb}$ di Sungai Batanghari Provinsi Sumatera Barat telah melebihi baku mutu untuk air minum sesuai PermenLH No. 82 Tahun 2001 sehingga dikategorikan tidak layak untuk dikonsumsi. Pencemaran logam berat termasuk pencemaran yang berbahaya karena dapat berdampak negatif terhadap manusia yang mengonsumsinya dan organisme yang terdapat di dalam badan air tersebut (Mohiuddin dkk, 2011).

Peningkatan dan kontinuitas buangan air limbah yang mengandung senyawa logam berat lambat laun dapat menyebabkan ekosistem sungai menjadi rusak. Hal ini dikarenakan kesukaran logam berat untuk melapuk, baik secara fisika, biologi, maupun kimia (Palar, 1994). Oleh karena itu, penelitian ini bertujuan untuk mengetahui kandungan logam berat $\mathrm{Hg}, \mathrm{Cd}, \mathrm{Pb}, \mathrm{Mn}$, dan $\mathrm{Fe}$ pada air
Sungai Batanghari Provinsi Jambi dan menentukan tingkat cemarannya dengan mengacu pada PP No. 82 Tahun 2001.

\section{Metode Penelitian}

\subsection{Lokasi Penelitian}

Lokasi penelitian ini dilakukan di wilayah Aur Duri 1 dan Aur Duri 2 Provinsi Jambi dan pengambilan sampel air dilakukan pada Sungai Batanghari yang dilakukan pada bulan Juli - Agustus 2020. Penelitian kandungan logam berat pada air dilakukan pada 6 titik pengukuran yang terdiri dari : 3 titik pengukuran di wilayah Aur Duri 1 bagian atas dan bawah sungai dan 3 titik pengukuran di wilayah Aur Duri 2 bagian atas dan bawah sungai. Penentuan titik pengambilan sampel air sungai dilakukan dengan menggunakan metode purposive sampling yang berdasarkan pada kemudahan akses, biaya dan waktu dalam pelaksanaan penelitian. Berikut titik - titik pengambilan sampel air sungai :

Tabel 1. Titik Pengambilan Sampel

\begin{tabular}{cc}
\hline Aur Duri 1 & Aur Duri 2 \\
\hline P1 (Hulu Sungai) & Q1 (Hulu Sungai) \\
P2 (Tengah Sungai) & Q2 (Tengah Sungai) \\
P3 (Hilir Sungai) & Q3 (Hilir Sungai) \\
\hline
\end{tabular}

\subsection{Alat dan Bahan}

Alat-alat yang digunakan di lapangan untuk penelitian ini, yaitu : (a) jerigen plastik untuk tempat sampel air; (b) Kamera untuk dokumentasi; dan (c) alat tulis. Sedangkan bahan yang digunakan dalam penelitian ini adalah sampel air Sungai Batanghari Provinsi Jambi.

\subsection{Analisis Laboratorium}

Analisis laboratorium dilakukan di (a) Balai Laboratorium Kesehatan Provinsi Jambi untuk pengujian logam Cd dan Pb; (b) Laboratorium UPTD BPSMB Jambi untuk pengujian logam Fe dan Mn; dan (c) Laboratorium Air Jurusan Teknik Lingkungan Unand Padang untuk pengujian logam $\mathrm{Hg}$. 


\subsection{Analisis Data}

Analisis data yang dilakukan meliputi analisis kualitas air pada parameter logam $\mathrm{Hg}, \mathrm{Cd}, \mathrm{Pb}, \mathrm{Fe}$, dan $\mathrm{Mn}$ yang dibandingkan dengan klasifikasi dan kriteria air yang diatur dalam PP No. 82 Tahun 2001. Penentuan tingkat cemaran logam berat pada air Sungai Batanghari Provinsi Jambi menggunakan rumus Lacatusu (2000) dalam Yanova dan Anita (2016) :

Indeks $\mathrm{C} / \mathrm{P}=\frac{\text { Konsentrasi Logam Berat pada Sampel }}{\text { Nilai Ambang Batas Logam Berat }}$

Tabel 2. Tingkat $\mathrm{C} / \mathrm{P}$ berdasarkan Indeks

\begin{tabular}{cc}
\hline Indeks $\mathrm{C} / \mathrm{P}$ & Tingkat $\mathrm{C} / \mathrm{P}$ \\
\hline 0 & Tidak terkontaminasi \\
$<0,1$ & Sangat sedikit terkontaminasi \\
$0,1-0,2$ & Sedikit terkontaminasi \\
$0,26-0,50$ & Cukup terkontaminasi \\
$0,51-0,75$ & Terkontaminasi berat \\
$0,76-1,00$ & Sangat terkontaminasi \\
$1,1-2,0$ & Sedikit tercemar \\
$2,1-4,0$ & Cukup tercemar \\
$4,1-8,0$ & Tercemar berat \\
$8,1-16,0$ & Sangat tercemar \\
$>16,0$ & Teramat sangat tercemar \\
\hline
\end{tabular}

\section{Hasil dan Pembahasan}

Hasil analisis kualitas air di Aur Duri 1 dan Aur Duri 2 Provinsi Jambi pada titik yang berbeda dan mengacu pada PP No. 82 Tahun 2001, yaitu sebagai berikut :

\subsection{Logam Merkuri (Hg)}

Hasil pengukuran $\mathrm{Hg}$ secara keseluruhan pada keenam titik sampel dapat dilihat pada Gambar 1 berikut ini:

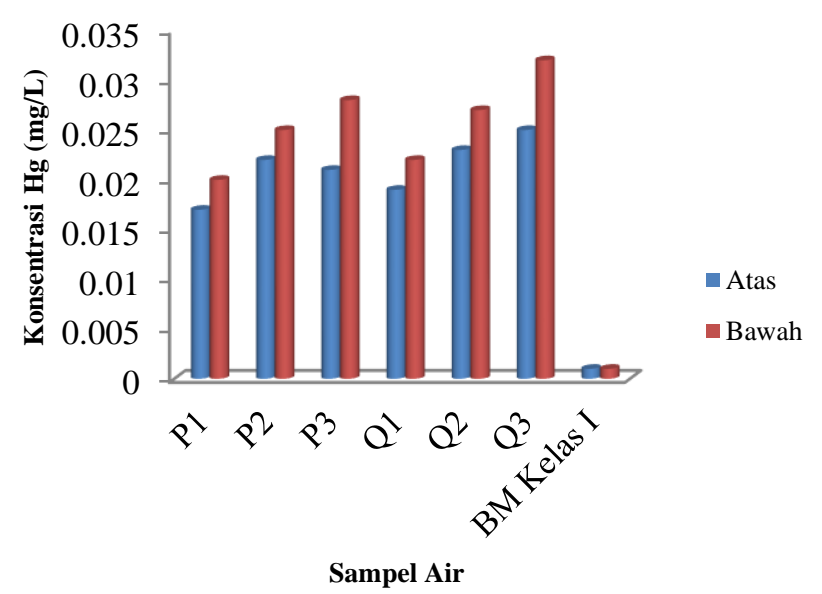

Gambar 1. Hasil Analisis Parameter Hg

Berdasarkan pada Gambar 1, diketahui bahwa semua sampel air Sungai Batanghari Provinsi Jambi telah melebihi standar baku mutu (BM) yang telah ditetapkan oleh PP No. 82 Tahun 2001 Kelas I, yaitu 0,001 mg/L. Adapun tingkat C/P berdasarkan pada perhitungan indeks $\mathrm{C} / \mathrm{P}$ dapat dilihat pada Tabel 3 berikut:
Tabel 3. Tingkat C/P Sampel Parameter $\mathrm{Hg}$

\begin{tabular}{cccc}
\hline Sampel & $\begin{array}{c}\text { Konsentrasi } \\
(\mathrm{mg} / \mathrm{L})\end{array}$ & $\begin{array}{c}\text { Indeks } \\
\mathrm{C} / \mathrm{P}\end{array}$ & Tingkat C/P \\
\hline P1A & 0,017 & 17 & Teramat sangat tercemar \\
P1B & 0,02 & 20 & Teramat sangat tercemar \\
P2A & 0,022 & 22 & Teramat sangat tercemar \\
P2B & 0,025 & 25 & Teramat sangat tercemar \\
P3A & 0,021 & 21 & Teramat sangat tercemar \\
P3B & 0,028 & 28 & Teramat sangat tercemar \\
Q1A & 0,019 & 19 & Teramat sangat tercemar \\
Q1B & 0,022 & 22 & Teramat sangat tercemar \\
Q2A & 0,023 & 23 & Teramat sangat tercemar \\
Q2B & 0,027 & 27 & Teramat sangat tercemar \\
Q3A & 0,025 & 25 & Teramat sangat tercemar \\
Q3B & 0,032 & 32 & Teramat sangat tercemar \\
\hline
\end{tabular}

Berdasarkan hasil yang diperoleh dari Tabel 3, diketahui bahwa seluruh sampel air Sungai Batanghari termasuk kategori teramat sangat tercemar logam merkuri $(\mathrm{Hg})$. Tingginya kandungan logam $\mathrm{Hg}$ pada air Sungai Batanghari Provinsi Jambi disebabkan oleh banyaknya aktivitas PETI (Penambangan Emas Tanpa Izin) di sepanjang sungai. Kebiasaan penambang yang membuang limbahnya ke sungai tanpa diolah terlebih dahulu menyebabkan kandungan logam merkuri sangat tinggi di dalam badan air.

\subsection{Logam Kadmium (Cd)}

Hasil pengukuran $\mathrm{Cd}$ secara keseluruhan pada keenam titik sampel dapat dilihat pada Gambar 2 berikut ini:

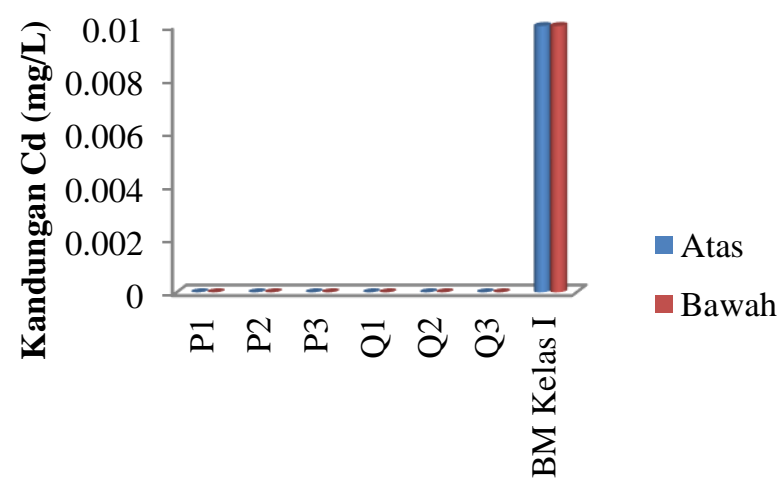

Sampel Air

Gambar 2. Hasil Analisis Parameter Cd

Berdasarkan pada Gambar 2, diketahui bahwa semua sampel air Sungai Batanghari Provinsi Jambi tidak melebihi standar baku mutu (BM) yang telah ditetapkan oleh PP No. 82 Tahun 2001 Kelas I, yaitu $0,01 \mathrm{mg} / \mathrm{L}$. Adapun tingkat C/P berdasarkan pada perhitungan indeks $\mathrm{C} / \mathrm{P}$ dapat dilihat pada Tabel 4 berikut:

Tabel 4. Tingkat $\mathrm{C} / \mathrm{P}$ Sampel Parameter $\mathrm{Cd}$

\begin{tabular}{cccc}
\hline Sampel & $\begin{array}{c}\text { Konsentrasi } \\
(\mathrm{mg} / \mathrm{L})\end{array}$ & Indeks C/P & Tingkat C/P \\
\hline P1A & $<0,014$ & 0 & Tidak terkontaminasi \\
P1B & $<0,014$ & 0 & Tidak terkontaminasi \\
P2A & $<0,014$ & 0 & Tidak terkontaminasi \\
P2B & $<0,014$ & 0 & Tidak terkontaminasi \\
P3A & $<0,014$ & 0 & Tidak terkontaminasi \\
\hline
\end{tabular}




\begin{tabular}{llll}
\hline P3B & $<0,014$ & 0 & Tidak terkontaminasi \\
Q1A & $<0,014$ & 0 & Tidak terkontaminasi \\
Q1B & $<0,014$ & 0 & Tidak terkontaminasi \\
Q2A & $<0,014$ & 0 & Tidak terkontaminasi \\
Q2B & $<0,014$ & 0 & Tidak terkontaminasi \\
Q3A & $<0,014$ & 0 & Tidak terkontaminasi \\
Q3B & $<0,014$ & 0 & Tidak terkontaminasi \\
\hline
\end{tabular}

Berdasarkan hasil yang diperoleh dari Tabel 4, diketahui bahwa seluruh sampel air Sungai Batanghari termasuk kategori tidak terkontaminasi logam kadmium $(\mathrm{Cd})$.

\subsection{Logam Timbal (Pb)}

Hasil pengukuran $\mathrm{Pb}$ secara keseluruhan pada keenam titik sampel dapat dilihat pada Gambar 3 berikut ini:

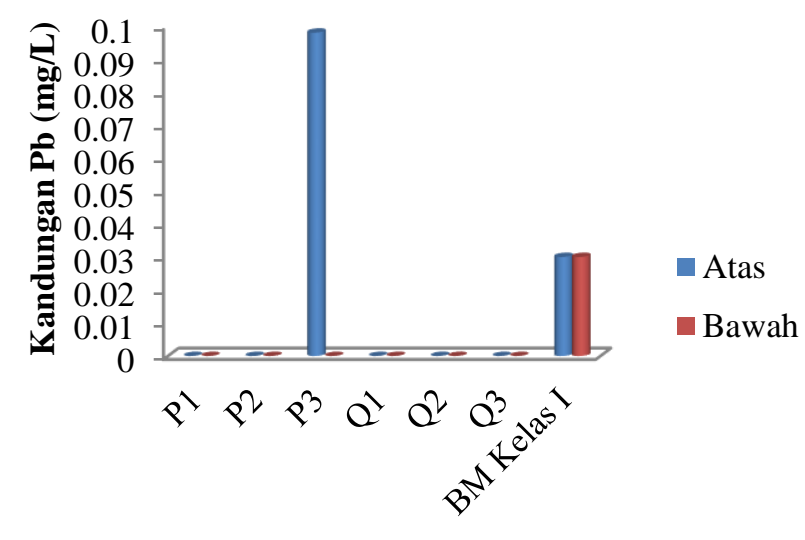

Sampel Air

Gambar 3. Hasil Analisis Parameter $\mathrm{Pb}$

Berdasarkan pada Gambar 3, diketahui bahwa hanya sampel P3A yang telah melebihi standar baku mutu (BM) yang telah ditetapkan oleh PP No. 82 Tahun 2001 Kelas I, yaitu $0,03 \mathrm{mg} / \mathrm{L}$. Sedangkan sampel lainnya tidak melebihi baku mutu yang telah ditetapkan. Adapun tingkat $\mathrm{C} / \mathrm{P}$ berdasarkan pada perhitungan indeks $\mathrm{C} / \mathrm{P}$ dapat dilihat pada Tabel 5 berikut:

Tabel 5. Tingkat $\mathrm{C} / \mathrm{P}$ Sampel Parameter $\mathrm{Pb}$

\begin{tabular}{cccc}
\hline Sampel & $\begin{array}{c}\text { Konsentrasi } \\
(\mathrm{mg} / \mathrm{L})\end{array}$ & Indeks C/P & Tingkat C/P \\
\hline P1A & $<0,02$ & 0 & Tidak terkontaminasi \\
P1B & $<0,02$ & 0 & Tidak terkontaminasi \\
P2A & $<0,02$ & 0 & Tidak terkontaminasi \\
P2B & $<0,02$ & 0 & Tidak terkontaminasi \\
P3A & 0,09795 & 3,265 & Cukup tercemar \\
P3B & $<0,02$ & 0 & Tidak terkontaminasi \\
Q1A & $<0,02$ & 0 & Tidak terkontaminasi \\
Q1B & $<0,02$ & 0 & Tidak terkontaminasi \\
Q2A & $<0,02$ & 0 & Tidak terkontaminasi \\
Q2B & $<0,02$ & 0 & Tidak terkontaminasi \\
Q3A & $<0,02$ & 0 & Tidak terkontaminasi \\
Q3B & $<0,02$ & 0 & Tidak terkontaminasi \\
\hline
\end{tabular}

Berdasarkan hasil yang diperoleh dari Tabel 5, diketahui bahwa hanya sampel air P3A yang termasuk kategori cukup tercemar logam timbal $(\mathrm{Pb})$, sedangkan sampel lainnya termasuk kategori tidak terkontaminasi logam $\mathrm{Pb}$.
Tingginya kandungan logam $\mathrm{Pb}$ pada titik sampel $\mathrm{P} 3 \mathrm{~A}$ disebabkan oleh bagian hilir Sungai Batanghari di Aur Duri 1 berdekatan dengan jalan yang sering dilalui oleh kendaraan bermotor.

\subsection{Logam Mangan (Mn)}

Hasil pengukuran Mn secara keseluruhan pada keenam titik sampel dapat dilihat pada Gambar 4 berikut ini:

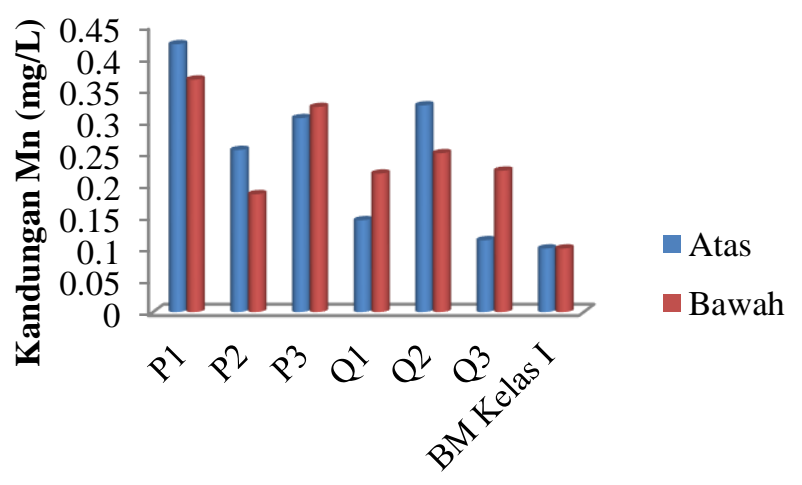

Sampel Air

Gambar 4. Hasil Analisis Parameter Mn

Berdasarkan pada Gambar 4, diketahui bahwa seluruh sampel air Sungai Batanghari Provinsi Jambi telah melebihi standar baku mutu (BM) yang telah ditetapkan oleh PP No. 82 Tahun 2001 Kelas I, yaitu $0,1 \mathrm{mg} / \mathrm{L}$. Adapun tingkat $\mathrm{C} / \mathrm{P}$ berdasarkan pada perhitungan indeks $\mathrm{C} / \mathrm{P}$ dapat dilihat pada Tabel 6 berikut:

Tabel 6. Tingkat C/P Sampel Parameter Mn

\begin{tabular}{cccc}
\hline Sampel & $\begin{array}{c}\text { Konsentrasi } \\
(\mathrm{mg} / \mathrm{L})\end{array}$ & Indeks C/P & Tingkat C/P \\
\hline P1A & 0,421 & 4,21 & Tercemar berat \\
P1B & 0,3655 & 3,655 & Cukup tercemar \\
P2A & 0,255 & 2,55 & Cukup tercemar \\
P2B & 0,1855 & 1,855 & Sedikit tercemar \\
P3A & 0,305 & 3,05 & Cukup tercemar \\
P3B & 0,3225 & 3,225 & Cukup tercemar \\
Q1A & 0,1445 & 1,445 & Sedikit tercemar \\
Q1B & 0,218 & 2,18 & Cukup tercemar \\
Q2A & 0,325 & 3,25 & Cukup tercemar \\
Q2B & 0,25 & 2,5 & Cukup tercemar \\
Q3A & 0,113 & 1,13 & Sedikit tercemar \\
Q3B & 0,2225 & 2,225 & Cukup tercemar \\
\hline
\end{tabular}

Berdasarkan hasil yang diperoleh dari Tabel 6, diketahui bahwa hanya sampel air P1A yang termasuk kategori tercemar berat logam Mn, sedangkan sampel P1b, P2A, P3A, P3B, Q1B, Q2A, Q2B, dan Q3B termasuk kategori cukup tercemar logam $\mathrm{Mn}$. Sedangkan sampel lainnya termasuk kategori sedikit tercemar logam Mn.

\subsection{Logam Besi (Fe)}

Hasil pengukuran Fe secara keseluruhan pada keenam titik sampel dapat dilihat pada Gambar 5 berikut ini: 


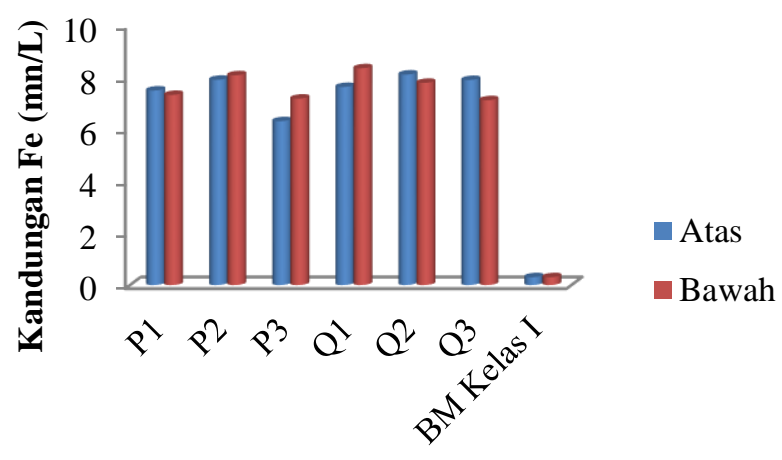

Sampel Air

Gambar 5. Hasil Analisis Parameter Fe

Berdasarkan pada Gambar 5, diketahui bahwa seluruh sampel air Sungai Batanghari Provinsi Jambi telah melebihi standar baku mutu (BM) yang telah ditetapkan oleh PP No. 82 Tahun 2001 Kelas I, yaitu $0,3 \mathrm{mg} / \mathrm{L}$. Adapun tingkat $\mathrm{C} / \mathrm{P}$ berdasarkan pada perhitungan indeks $\mathrm{C} / \mathrm{P}$ dapat dilihat pada Tabel 7 berikut:

Tabel 7. Tingkat C/P Sampel Parameter Fe

\begin{tabular}{cccc}
\hline Sampel & $\begin{array}{c}\text { Konsentrasi } \\
(\mathrm{mg} / \mathrm{L})\end{array}$ & $\begin{array}{c}\text { Indeks } \\
\mathrm{C} / \mathrm{P}\end{array}$ & Tingkat C/P \\
\hline P1A & 7,497 & 24,99 & Teramat sangat tercemar \\
P1B & 7,3275 & 24,425 & Teramat sangat tercemar \\
P2A & 7,912 & 26,373 & Teramat sangat tercemar \\
P2B & 8,0855 & 26,952 & Teramat sangat tercemar \\
P3A & 6,3115 & 21,038 & Teramat sangat tercemar \\
P3B & 7,184 & 23,947 & Teramat sangat tercemar \\
Q1A & 7,633 & 25,443 & Teramat sangat tercemar \\
Q1B & 8,358 & 27,86 & Teramat sangat tercemar \\
Q2A & 8,1155 & 27,052 & Teramat sangat tercemar \\
Q2B & 7,793 & 25,977 & Teramat sangat tercemar \\
Q3A & 7,9045 & 26,348 & Teramat sangat tercemar \\
Q3B & 7,1225 & 23,742 & Teramat sangat tercemar \\
\hline
\end{tabular}

Berdasarkan hasil yang diperoleh dari Tabel 7, diketahui bahwa seluruh sampel air Sungai Batanghari Provinsi Jambi termasuk kategori teramat sangat tercemar logam Fe.

\section{Kesimpulan}

Berdasarkan hasil penelitian ini, dapat disimpulkan bahwa air Sungai Batanghari Provinsi Jambi telah teramat sangat tercemar logam $\mathrm{Hg}$ dan Fe, jika mengacu pada PP No. 82 Tahun 2001 Kelas I. Kandungan logam Mn dalam air Sungai Batanghari mayoritas termasuk kategori cukup tercemar logam Mn. Sedangkan kandungan logam $\mathrm{Cd}$ dan $\mathrm{Pb}$ termasuk kategori tidak terkontaminasi.

\section{Daftar Pustaka}

Asdak C. (2010). Hidrologi dan Pengelolaan Daerah Aliran Sungai. Yogyakarta : Gajah Mada University Press.

Baherem. (2014). Strategi Pengelolaan Sungai Berdasarkan Daya Tampung Beban Pencemaran dan Kapasitas Asimilasi, Studi Kasus: Sungai Cibanten Provinsi
Banten. Tesis. Bogor : Sekolah Pascasarjana Institut Pertanian Bogor.

Mohiuddin KM, Ogawa, Y, Zakir, HM, Otomo, K, Shikazono, N. (2011). Heavy metals contamination in the water and sediments of an urban river in a developing country. International Journal of Environmental Science and Technolog, 8:723-736.

Palar H. (1994). Pencemaran dan Toksikologi Logam Berat. Jakarta : Rineka Cipta.

Peraturan Pemerintah No. 82 Tahun 2001 tentang Pengelolaan Kualitas Air dan Pengendalian Pencemaran Air.

Rahman KMS. (2011). Implementasi Peraturan Pemerintah No. 82 Tahun 2001 dan Peraturan Menteri Kesehatan No. 416 Tahun 1990 Di Instalasi Pengelolaan Air PDAM Kabupaten Pacitan Tahun 2011. Tesis. Program Pascasarjana Universitas Sebelas Maret Surakarta.

Sahara R. dan Puryanti D. (2015). Distribusi Logam Berat Hg dan Pb Pada Sungai Batanghari Aliran Batu Bakanik Dharmasraya, Sumatera Barat. Jurnal Fisika Unand, 4(1):68-77.

Wiriani ERE, Yarifudin H, Jalius. (2018). Analisis Kualitas Air Sungai Batanghari Berkelanjutan di Kota Jambi. Jurnal Pembangunan Berkelanjutan, 1(1):123-141.

Wiwoho. (2005). Model identifikasi Daya Tampung Beban Cemaran Sungai Dengan QUAL2E - Study kasus Sungai Babon. Semarang : Universitas Diponegoro.

Yanova S. dan Anita S. (2016). Analisis Tingkat Cemaran Logam Tembaga dan Tingkat Pendapatan Usahatani Sayuran di Kebun Kartama dan Kebun KOMPPOS-EM Kota Pekanbaru. Photon: Jurnal Sain dan Kesehatan, 6(02):115-121. 